patients. In this study, we have shown that inkwelling significantly increases the incidence of benign anastomotic stricture after Ivor Lewis esophagogastrectomy without affecting that rate of anastomotic dehiscence. Of note is that our study shows a high rate of benign anastomotic stricture. A similar incidence of benign anastomotic stricture has been reported in other series. ${ }^{4}$ The incidence of stricture is influenced considerably by its definition and the quality of follow-up. In our center, patients are followed up every 6 months for life, and this may explain our high stricture detection rate.

Our study is limited by the fact that it is a retrospective nonrandomized study; therefore, we were not able to control for other factors that may have influenced stricture formation, for example, staple size. ${ }^{5}$

In conclusion, life expectancy is limited in most patients after Ivor Lewis esophagogastrectomy; 5-year survival in our unit is $22 \%,{ }^{2}$ and so for the majority of patients the benefit of the procedure is excellent palliation with rapid and long-term relief of dysphagia. The development of anastomotic stricture therefore reduces the benefit of the operation and casts doubts on the utility of palliation. Inkwelling of the gastroesophageal anastomosis increases benign anastomotic stricture formation.

\section{References}

1. Procter DS. The 'ink-well' anastomosis in oesophageal reconstruction. $S$ Afr Med J. 1967:25;41:187-90.

2. Junemann-Ramirez M, Awan MY, Khan ZM, Rahamim JS. Anastomotic leakage post-esophagogastrectomy for esophageal carcinoma: retrospective analysis of predictive factors, management and influence on longterm survival in a high volume centre. Eur J Cardiothorac Surg.2005:27;3-7.

3. Lam TC, Fok M, Cheng SW, Wong J. Anastomotic complications after esophagectomy for cancer: a comparison of neck and chest anastomoses. J Thorac Cardiovasc Surg.1992:104;395-400.

4. Honkoop P, Siersema PD, Tilanus HW, Stassen LP, Hop WC, van Blankenstein M. Benign anastomotic strictures after transhiatal esophagectomy and cervical esophagogastrostomy: risk factors and management. J Thorac Cardiovasc Surg.1996:111;1141-6.

5. Pierie JP, de Graaf PW, Poen H, van der Tweel I, Obertop H. Incidence and management of benign anastomotic stricture after cervical oesophagogastrostomy. Br J Surg.1993:80;471-4.

\title{
Tuberculosis presenting as an endobronchial mass
}

Daniel Kreisel, MD, PhD, ${ }^{a}$ Nimmi Arora, MD, ${ }^{\mathrm{b}}$ Scott A. Weisenberg, MD, ${ }^{c}$ Anjali Saqi, MD, ${ }^{d}$ Alexander S. Krupnick, MD, ${ }^{a}$ Anna M. Demetriades, MD, ${ }^{\mathrm{b}}$ Chris lakovou, MD, ${ }^{\mathrm{e}}$ Rick Conetta, MD, ${ }^{\mathrm{e}}$ and Paul C. Lee, MD, ${ }^{\mathrm{b}}$ St Louis, Mo, and New York, NY

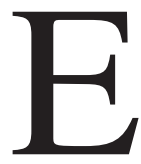
ndobronchial tuberculosis has become a rare condition in developed countries. Furthermore, tuberculosis is often not considered in the differential diagnosis of endobronchial masses. Thus diagnosis is often delayed because of the rarity of this condition and the nonspecific nature of the symptoms. This case report describes endobronchial tuberculosis in a young previously healthy woman.

\section{Clinical Summary}

A 25-year-old woman with a past history of asthma presented with new onset of a dry cough. This was associated with symptoms of

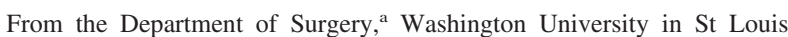
St Louis, Mo; the Departments of Cardiothoracic Surgery, ${ }^{\mathrm{b}}$ Medicine, ${ }^{\mathrm{c}}$ and Pathology, ${ }^{\mathrm{d}}$ Weill Medical College of Cornell University, New York, NY; and the Department of Medicine, ${ }^{\mathrm{e}}$ New York Hospital Queens, New York, NY

Received for publication April 25, 2006; accepted for publication Sept 28, 2006.

Address for reprints: Daniel Kreisel, MD, PhD, Department of Surgery, Washington University, Campus Box 8234, 600 S Euclid Ave, St Louis, MO 63110 (E-mail: kreiseld@wudosis.wustl.edu).

J Thorac Cardiovasc Surg 2007;133:582-4

$0022-5223 / \$ 32.00$

Copyright $\odot 2007$ by The American Association for Thoracic Surgery doi:10.1016/j.jtcvs.2006.09.040 fatigue and anorexia. The patient had emigrated from the Philippines to the United States several years ago and had been employed as an office manager in a garment store for the last 18 months. A PPD tuberculin skin test result was negative when she started that employment. A few weeks after the onset of her cough, she had right-sided pleuritic chest pain and worsening shortness of breath. A chest radiograph showed an opacity in her right lower lung field. She was thought to have pneumonia and was started on oral antibiotics. Because her symptoms failed to improve, a chest computed tomographic scan was obtained that demonstrated dense consolidation of her right middle and right lower lobes. It also showed an endobronchial lesion in her right mainstem bronchus at the level of the takeoff of her right upper lobe bronchus (Figure 1). Of note, bronchoalveolar lavage smears obtained at this initial flexible bronchoscopy were negative for acid-fast bacilli, and she was referred to the thoracic surgery service. Flexible bronchoscopy at our institution showed an endobronchial mass in her right mainstem bronchus opposite the orifice of her right upper lobe bronchus. This mass was nearly totally obstructing the airway and was covered with caseous material. The mass was cored out with a rigid bronchoscope. Histologic examination revealed necrotizing granulomatous inflammation, and rare mycobacterial organisms were demonstrated with acid-fast stain (Figure 2). A PPD tuberculin skin test result was positive, with an induration of $20 \mathrm{~mm}$ at 48 hours. Of note, she had negative test results for HIV. The patient was treated with isoniazid, rifampin (INN: rifampicin), 


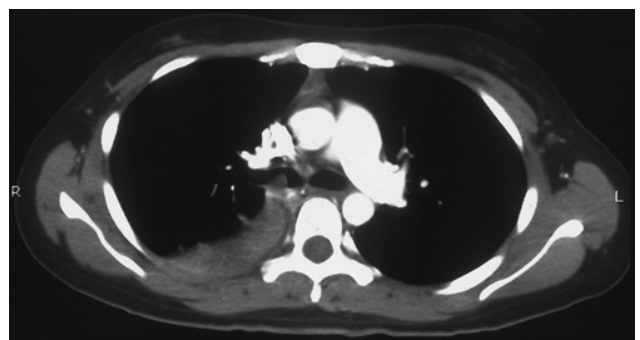

Figure 1. Chest computed tomography demonstrates an endobronchial mass on the posterior wall of the right mainstem bronchus at the level of the takeoff of the right upper lobe bronchus.

ethambutol, and pyrazinamide. Cultures at 4 weeks grew Mycobacterium tuberculosis. The patient remains asymptomatic at 6-month follow-up, with a chest radiograph demonstrating clear lung fields.

\section{Discussion}

Endobronchial tuberculosis is thought to be secondary to implantation from an adjacent parenchymal focus, to result from rupture of a lymph node, or to be secondary to extension to the peribronchial region by lymphatic drainage. Although the precise incidence of endobronchial lesions in patients with tuberculosis might be underestimated because of the infrequent use of bronchoscopy, endobronchial tuberculosis has become a rare clinical entity in developed countries as effective chemotherapeutic agents have been introduced. Therefore tuberculosis is often not taken into consideration in the differential diagnosis of endobronchial lesions. In addition, the diagnosis is often delayed because findings on chest radiographs are nonspecific, and the diagnostic rate of smears from sputum or bronchoalveolar fluid can be low. Computed tomography can demonstrate the presence of endobronchial lesions, as was the case in our patient. It is important to note that patients with endobronchial tuberculosis have a high incidence of positive sputum samples, which represents a public health concern. Endobronchial tuberculosis has been classified bronchoscopically into 7 subtypes: actively caseating, edematous-hyperemic, fibrostenotic, tumorous, granular, ulcerative, and nonspecific bronchitic. ${ }^{1}$ The actively caseating form can progress to the fibrostenotic subtype and result in airway stenosis, the most critical complication of this entity.

The timely diagnosis of endobronchial tuberculosis and expeditious initiation of treatment is of critical importance. During the active stage of the disease, chemotherapeutic agents have been shown to be efficient at eradicating tubercle bacilli. Moreover, if endobronchial tuberculosis is suspected, debridement of the lesion before initiation of antituberculosis treatment is not advisable because it can lead to dissemination of the infection and might predispose to formation of fistulas. Although a prospective study failed to show a benefit with the use of systemic corticosteroids, one report suggested that aerosol therapy with streptomycin and corticosteroids during the early stages of endobronchial tubercu-
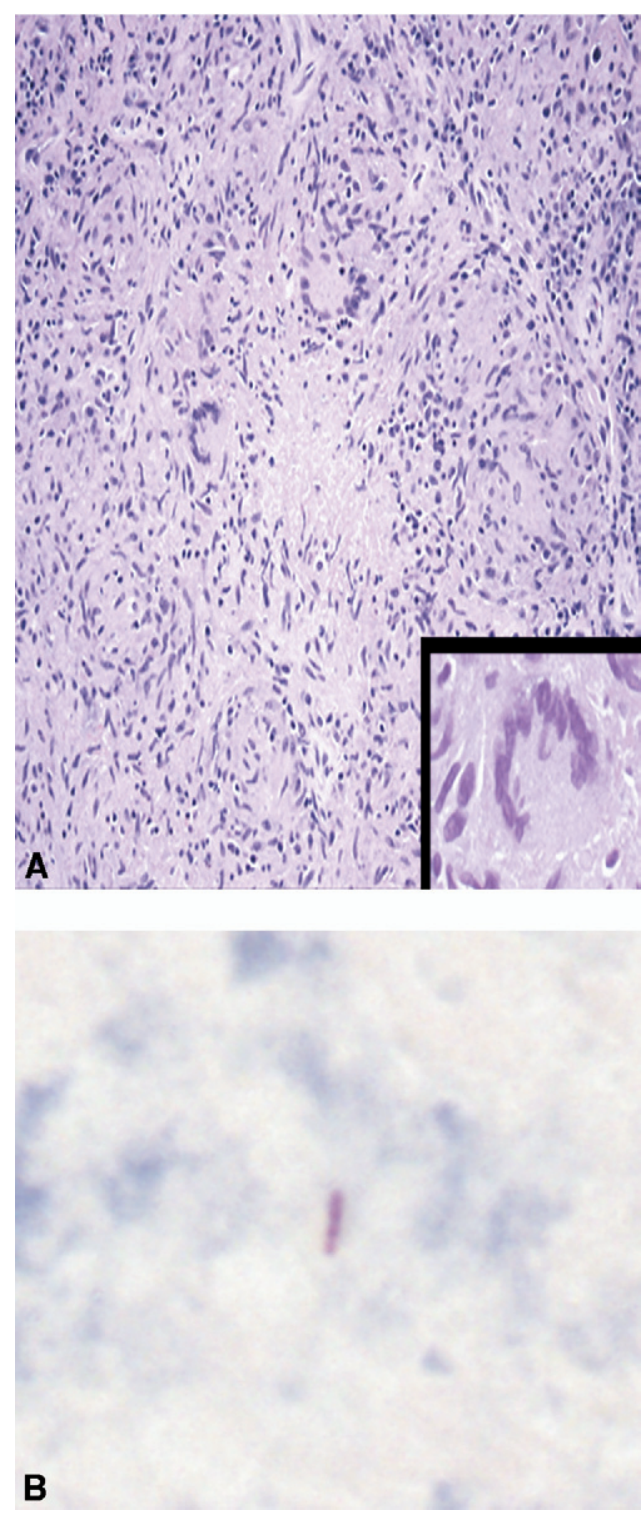

Figure 2. A, Histopathologic examination of the endobronchial mass demonstrates a granuloma with multinucleated giant cells and central caseous necrosis. (Hematoxylin and eosin, original magnification $10 \times$.) The inset shows higher magnification of multinucleated giant cell. (Hematoxylin and eosin, original magnification $60 \times$.) B, Acid-fast stain demonstrates thin rod-like mycobacterium (Original magnification $60 \times$.)

losis might be beneficial in preventing progression to fibrostenosis. ${ }^{2,3}$ Corticosteroids or other medical regimens cannot reverse airway fibrosis, and airway stenosis is inevitable if the disease is allowed to progress to the fibrostenotic subtype. Endobronchial ultrasonography has been used to guide the treatment of airway stenosis caused by endobronchial tuberculosis. Various interventional endobronchial techniques, such as laser ablation, balloon dilatation, or stent placement, have been used in its treatment. ${ }^{4}$ 
In more advanced cases, bronchoplastic procedures have been reported. ${ }^{5}$

In conclusion, this case highlights an unusual presentation of tuberculosis. A high index of suspicion is warranted to make a timely diagnosis of endobronchial tuberculosis and initiate early treatment. Serial bronchoscopies will be required in this patient to assess the degree of airway stenosis.

\section{References}

1. Chung HS, Lee JH. Bronchoscopic assessment of the evolution of endobronchial tuberculosis. Chest. 2000;117:385-92.
2. Park IW, Choi BW, Hue SH. Prospective study of corticosteroids as an adjunct in the treatment of endobronchial tuberculosis in adults. Respirology. 1997;2:275-81.

3. Rikimaru T, Koga T, Sueyasu Y, Ide S, Kinosita M, Sugihara E, et al. Treatment of ulcerative endobronchial tuberculosis and bronchial stenosis with aerosolized streptomycin and steroids. Int J Tuberc Lung Dis. 2001;5:769-74.

4. Iwamoto Y, Miyazawa T, Kurimoto N, Miyazu y, Ishida A, Matsuo $\mathrm{K}$, et al. Interventional bronchoscopy in the management of airway stenosis due to tracheobronchial tuberculosis. Chest. 2004;126: 1344-52.

5. Kato R, Kakizaki T, Hangai N, Sawafuji M, Yamamoto T, Kobayashi $\mathrm{T}$, et al. Bronchoplastic Procedures for tuberculous bronchial stenosis. J Thorac Cardiovasc Surg. 1993;106:1118-21.

\title{
Lymphoceles in premature infants after congenital diaphragmatic hernia repair: Thoracoscopic management
}

\author{
Amulya K. Saxena, MD, Emir Haxihja, MD, Barbara Kleinlein, MD, and Michael E. Höllwarth, MD, Graz, Austria
}

$\mathrm{P}$ olytetrafluoroethylene (PTFE) is a prosthetic material used for congenital diaphragmatic hernia $(\mathrm{CDH})$ closure that has been associated with low morbidity. We report the case of a 2150-g premature newborn with a left-sided diaphragmatic hernia managed with PTFE. Heparin therapy was initiated because of an inferior vena caval thrombosis formed as a result of an indwelling umbilical catheter placed after birth. During the postoperative course, left thoracic lymphoceles developed that increased in volume, leading to bouts of respiratory distress. The lymphoceles could be successfully managed with minimal invasive thoracoscopic surgery.

\section{Clinical Summary}

A premature newborn (III/II; male; birth weight, $2150 \mathrm{~g}$; gestational age, 33 weeks and 1 day) with a left-sided CDH diagnosed antenatally was delivered by means of cesarean section because of premature detachment of the placenta in a pregnancy complicated throughout by vaginal bleeding. The newborn presented with Apgar scores of 5/8/8 and was intubated immediately after birth because of the presence of pulmonary hypoplasia (arterial blood gas, $\mathrm{pH}$ 7.24; $\mathrm{PCO}_{2}, 59 \mathrm{~mm} \mathrm{Hg} ; \mathrm{Po}_{2}, 357 \mathrm{~mm} \mathrm{Hg}$ ) and accompanying hypotension (blood pressure, $47 / 36 \mathrm{~mm} \mathrm{Hg}$; mean arterial

\footnotetext{
From the Department of Pediatric Surgery, Medical University of Graz, Graz, Austria.

Received for publication Aug 29, 2006; accepted for publication Sept 25, 2006.

Address for reprints: Amulya K. Saxena, MD, Department of Pediatric Surgery, Medical University of Graz, Auenbruggerplatz 34, A-8034 Graz,

Austria (E-mail: Amulya.Saxena@klinkum-graz.at).

J Thorac Cardiovasc Surg 2007;133:584-5

$0022-5223 / \$ 32.00$

Copyright $\odot 2007$ by The American Association for Thoracic Surgery doi:10.1016/j.jtcvs.2006.09.039
}

pressure, $23 \mathrm{~mm} \mathrm{Hg}$ ). Ventilatory support with the intermittent application of surfactant and nitric oxide, as well as circulatory support with catecholamine, was carried out for 4 days. On the fifth day, under stable cardiorespiratory conditions, the patient was operated on for the left-sided $\mathrm{CDH}$.

Laparotomy revealed the presence of the stomach, spleen, and small and large bowels in the left thoracic cavity. After reducing the herniated organs, it was not possible to directly approximate the diaphragmatic defect, and a PTFE patch (Gore-Tex Soft Tissue Patch; W.L. Gore \& Associates, Inc, Flagstaff, Ariz) of $1 \times 1 \mathrm{~cm}$ was sutured to close the hernia. A femoral vein catheter was inserted to the level of the inferior vena cava to gain adequate vascular access for the procedure and postoperative management.

Two weeks after the operation, increased prominence of the abdominal veins was observed, and an ultrasonographic examination was performed. The results revealed an inferior vena caval thrombus extending from the catheter tip to the right atrium. The catheter was removed, and low-dose heparin (20 IU $\cdot \mathrm{kg}^{-1} \cdot \mathrm{h}^{-1}$ ) prophylaxis was initiated.

Four weeks after the procedure, pleural effusions in the left thorax manifested as signs of dyspnea. On x-ray films, the effusions were peculiar in the fact that they were located throughout the left thorax and exerted hydrostatic pressure on the relatively smaller ipsilateral lung. Thoracocentesis $(50 \mathrm{~mL}$ of cloudy secretion with a triglyceride count of $638 \mathrm{mg} / \mathrm{dL}$ and lymphocytes) was performed, and the infant was weaned from mechanical ventilation. Initially, this pleural effusion was presumed to be a result of unnoticed injury to the thoracic duct during the operation, and total parenteral nutrition was commenced.

However, 1 week later, the pleural effusions reappeared in the left thorax. Approximately $45 \mathrm{~mL}$ and $50 \mathrm{~mL}$ of blood-tinged secretion were evacuated on consecutive days. Despite thoracocentesis, the infant presented with increased respiratory distress. A reintubation was performed, and a chest tube was placed in the left 